\title{
Viabilidade da incorporação do lodo de estação de tratamento de esgoto (ETE) em massa cerâmica para produção de blocos
}

\section{(Viability of use of sludge from sewage treatment plant in the ceramic mass production of ceramic bricks)}

\author{
C.R. L. da Silva, A. L. Chinelatto, A. S. A. Chinelatto \\ Programa de Mestrado em Engenharia e Ciência de Materiais, Universidade Estadual de Ponta Grossa, Av. Carlos \\ Cavalcanti 4748, Uvaranas, Ponta Grossa, PR 84030-900 \\ celialucas.eng@gmail.com,adilson@uepg.br,adriana@uepg.br
}

\begin{abstract}
Resumo
O lodo gerado nas estações de tratamento de esgoto tem se tornado um problema crescente sendo considerado como resíduo. Este trabalho estudou a viabilidade da incorporação do lodo de estação de tratamento de esgoto (ETE) em massa cerâmica para produção de blocos. Para isso, amostras de lodo foram coletadas na ETE Verde da SANEPAR no Município de Ponta Grossa, PR e de argila da Cerâmica S. Gerônimo no município de Prudentópolis, PR. O lodo na ETE Verde foi submetido a um processo de higienização, o qual reduz significativamente a concentração de patógenos no resíduo. O processo utilizado foi a caleação, que promove a estabilização, desinfecção química e térmica através da adição e mistura da cal ao lodo numa porcentagem de $30 \%$ a $50 \%$ da massa seca de lodo. Para a caracterização do lodo e da argila foram realizadas análises de difração de raios X, análise térmica diferencial e termogravimétrica, fluorescência de raios X e distribuição granulométrica. Foram estudadas composições com adições de 5 a $50 \%$ em massa do lodo na massa cerâmica. Após a mistura do lodo com as argilas, as amostras foram conformadas por prensagem uniaxial e sinterizadas a $900{ }^{\circ} \mathrm{C}, 1000{ }^{\circ} \mathrm{C}$ e $1100{ }^{\circ} \mathrm{C}$. As amostras sinterizadas foram caracterizadas por medidas de absorção de água, porosidade aparente, resistência mecânica, difração de raios X e microscopia eletrônica de varredura. Os resultados mostraram que a adição do lodo até $25 \%$ da massa da argila atende a todos os parâmetros preconizados pelas normas vigentes para fabricação dos blocos cerâmicos.
\end{abstract}

Palavras-chave: blocos cerâmicos, lodo de ETE, resíduo sólido.

\begin{abstract}
The sludge generated in sewage treatment plants has become a growing problem and it is considered waste. This work aims to verify the feasibility of incorporating the sludge from sewage treatment plants $(S T P)$ in the ceramic slurry for the production of bricks. In order to do so, sludge samples were collected at the ETE Verde SANEPAR (a sewage treatment plant) in the city of Ponta Grossa, PR, Brazil, and clay samples at S. Gerônimo Ceramics in Prudentópolis, PR, Brazil. The sludge at the ETE Verde undergoes a cleaning process, significantly reducing the concentration of pathogens in the waste. The process used is 'liming', which promotes stabilization, thermal and chemical disinfection through the addition and mixing of lime into the sludge in a percentage from $30 \%$ to $50 \%$ of the dry weight of the sludge. For the characterization of sludge and clay, X-ray diffraction, differential thermal and thermogravimetric analysis, X-ray fluorescence and particle size distribution were carried out. The compositions studied were made with additions from 5 to 50\% per weight of the sludge in the ceramic slurry. After the mixing of the sludge with the clay, the samples were processed by uniaxial pressing and sintered at temperatures of $900^{\circ} \mathrm{C}, 1000{ }^{\circ} \mathrm{C} \mathrm{e} 1100^{\circ} \mathrm{C}$. The sintered samples were characterized by measurements of apparent density, water absorption, apparent porosity, mechanical strength, X-ray diffraction and scanning electron microscopy. The results showed that the addition of sludge up to $20 \%$ of the slurry of the clay meets all parameters recommended by current standards for production of bricks.
\end{abstract}

Keywords: bricks, sludge, waste.

\section{INTRODUÇÃO}

O crescimento populacional acelerado juntamente com o conjunto de atividades humanas resulta na contínua e desenfreada geração de resíduos pelo homem, os quais muitas vezes não apresentam destinação correta. Tanto residências, como todos os ramos industriais, de transporte, de saúde, do setor público, etc., são pontos geradores de resíduos em diferentes quantidades e características. A preocupação com a escassez dos recursos naturais e a poluição do meio ambiente culminou na criação de legislação específica [1] para o reaproveitamento e destinação correta desses resíduos.

O Plano Nacional de Resíduos Sólidos [2] apresenta dados recentes a respeito do diagnóstico da situação dos resíduos no Brasil e aponta a urgência da necessidade de tratamento e a sua adequada destinação.

Um resíduo produzido em grande quantidade é o lodo da Estação de Tratamento de Esgoto (ETE). O termo lodo 
de esgoto é utilizado para denominar o resíduo resultante do processo de tratamento de esgoto. Estima-se que a Sanepar, empresa responsável pelo tratamento de esgoto do Município de Ponta Grossa, PR atende a uma população de 305.624 habitantes. Segundo a NBR 7229 da ABNT, uma pessoa produz de 150 a 200 litros de esgoto por dia, considerando a sua produção residencial em área urbana [3].

Uma alternativa adotada de destinação final do lodo em muitas regiões do Brasil é o envio para aterros sanitários. Essa solução apresenta custo elevado e tem deficiência de áreas físicas em aterros devido à crescente demanda da geração do lodo de esgoto. Outra opção é uso do lodo na agricultura, técnica adotada em muitos países da Europa e com pesquisa em ascensão no Brasil. Com essa aplicação surge a necessidade do controle dos metais pesados presentes no lodo, provenientes de processos industriais, e ainda fica vetado o seu uso na horticultura e demais produtos consumidos crus que tenham contato direto com o lodo [4-6]. Outra problemática refere-se à extração de recursos naturais usados na fabricação de produtos cerâmicos. Uma das matérias-primas naturais mais usadas na produção de cerâmica é a argila. As argilas encontram-se normalmente em várzeas, planícies laterais de rios, zonas estas consideradas de proteção ambiental ou áreas de preservação permanente de acordo com o novo código florestal [7].

A indústria cerâmica é uma das que mais se destaca na reciclagem de resíduos industriais e urbanos, pois possui uma elevada produção, o que permite que um grande volume de resíduo seja utilizado. Além disso, as características físico-químicas das matérias-primas e o seu processamento favorecem a incorporação desses resíduos na massa cerâmica. Outro ponto a ser destacado é que para o processo produtivo a incorporação dos resíduos pode ser vantajosa, uma vez que reduz o consumo de matérias-primas, o consumo de energia, consequentemente, reduzindo os custos de produção [8]. Assim, a incorporação de resíduos como matéria-prima para a indústria cerâmica aplica a prática da destinação correta e reciclagem do resíduo reduzindo a extração de matériasprimas do meio ambiente e evitando a degradação de áreas nativas.

As principais vantagens de reciclar um resíduo são: preservar os recursos naturais (menor consumo de matériaprima), proteger o meio ambiente (menor quantidade de resíduos a serem dispostos) e poupar energia (no processo de transporte, entre outros) [9].

$\mathrm{Na}$ área acadêmica, a possibilidade da incorporação de resíduos na fabricação de produtos cerâmicos vem sendo estudada com frequência [10-13]. Quando se estuda a incorporação de lodo em produtos cerâmicos, as pesquisas são focadas, em sua maioria, na incorporação do resíduo da ETA (Estação de Tratamento de Água) [14-17], no entanto, trabalhos com a incorporação de lodo da ETE encontram-se em ascensão $[18,19]$. A presença do lodo na composição de materiais cerâmicos pode alterar suas propriedades. Foram sugeridas porcentagens de até $8 \%$ em massa de adição de lodo da ETA para não comprometer as propriedades finais do material cerâmico [15].
$\mathrm{O}$ presente trabalho teve como objetivo estudar a viabilidade da incorporação do resíduo da ETE (Estação de Tratamento de Esgoto) na massa cerâmica para a produção de blocos, visando à conservação dos recursos naturais, diminuindo o consumo de matérias-primas da natureza, amenizando o impacto ao meio ambiente e sugerindo uma opção de destinação para esse resíduo.

\section{MATERIAIS E MÉTODOS}

As argilas utilizadas neste estudo são naturais do Município de Prudentópolis, PR, onde são empregadas na fabricação de tijolos e blocos vazados pela Cerâmica $\mathrm{S}$. Gerônimo. O lodo foi coletado na Estação de Tratamento de Esgoto (ETE-Verde) da SANEPAR em Ponta Grossa, $\mathrm{PR}, \operatorname{logo}$ após o tratamento do esgoto. O lodo na ETE-Verde foi submetido a um processo de higienização, o qual reduz significativamente a concentração de patógenos no resíduo. No processo de tratamento, o esgoto foi canalizado até a ETE (Estação de Tratamento de Esgoto), onde foi bombeado até o sistema de gradeamento e desaneradores (caixas de areia) para a separação da matéria sólida grosseira. Em seguida, o esgoto passou por um medidor de vazão (calha Parshal) e então foi lançado nas unidades de reatores sofrendo um processo de tratamento biológico natural, decompondo e estabilizando a matéria orgânica pela ação de microrganismos anaeróbios. Depois de tratado, o lodo gerado foi higienizado e depositado no leito de secagem e o efluente lançado na lagoa de estabilização. O processo de higienização, o qual reduz significativamente a concentração de patógenos no resíduo é denominado de caleação, e promove a estabilização, desinfecção química e térmica por meio da adição e mistura da cal ao lodo numa porcentagem de $30 \%$ a $50 \%$ da massa seca de lodo.

As matérias-primas foram caracterizadas a partir da determinação da sua composição química feita por fluorescência de raios X (Shimadzu, EDX-7000); da determinação da distribuição de tamanho de partículas (Shimadzu SALD-220) e da determinação da sua composição mineralógica feita por difração de raios X (Shimadzu, XRD-6000). Para as medidas de distribuição de tamanho de partículas, os pós foram dispersos em água e submetidos a 1 min de ultrasom para dispersar as partículas. Para a realização da difração de raios $\mathrm{X}$ foi utilizada radiação $\mathrm{Cu}-$ $\mathrm{K} \alpha, \operatorname{com} 2 \theta$ variando de $2^{\circ}$ a $80^{\circ}$ e velocidade de varredura de $2 \% \mathrm{~min}$. Na análise de fluorescência de raios $\mathrm{X}$ foi utilizado uma fonte de raios $\mathrm{X}$ de $\mathrm{Rh}$, com um colimador de $10 \mathrm{~mm}$, tempo de contagem de $100 \mathrm{~s}$ e faixa de energia do Ti-U (50kV) e do Na-Sc (15kV).

As decomposições térmicas, reações e perdas de massa das matérias-primas foram analisadas a partir da análise térmica diferencial associada à análise termogravimétrica na faixa de temperatura de $25{ }^{\circ} \mathrm{C}$ a $1150{ }^{\circ} \mathrm{C}$, com uma taxa de aquecimento de $10{ }^{\circ} \mathrm{C} /$ minuto, com atmosfera de $\mathrm{N}_{2}$, em um equipamento de análise térmica da marca Netzsch modelo STA 409EP. Para esses ensaios de caracterização, as matérias-primas foram secadas em estufa a uma temperatura 
de $105{ }^{\circ} \mathrm{C}$ por $24 \mathrm{~h}$, em seguida foram cominuídas em almofariz de porcelana e passadas em peneira com abertura 0,180 mm (\# 80 ABNT).

Para a preparação das composições estudadas, inicialmente foi preparada uma amostra referência que consistia na mistura das duas argilas utilizadas na Cerâmica São Gerônimo. As argilas foram misturadas em moinhos de bolas com a adição de $2 \%$ em massa de silicato de sódio, como defloculante, por $6 \mathrm{~h}$. Em seguida foram secadas em estufa por $24 \mathrm{~h}$ a $110{ }^{\circ} \mathrm{C}$. A mistura seca foi então destorroada em almofariz de porcelana e passada em peneira com abertura 0,180 mm (\# 80 ABNT). A essa mistura foi adicionada diferentes quantidades de lodo, que variaram de 5 a $50 \%$ em massa. Na Tabela I são apresentadas as composições estudadas.

Tabela I - Composições estudadas. [Tabela I - Studied compositions.]

\begin{tabular}{ccc}
\hline Composição & $\begin{array}{c}\text { \% Argilas } \\
\text { (em massa) }\end{array}$ & $\begin{array}{c}\% \text { Lodo } \\
\text { (em massa) }\end{array}$ \\
\hline 1 & 100 & 0 \\
2 & 95 & 5 \\
3 & 90 & 10 \\
4 & 85 & 15 \\
5 & 80 & 20 \\
6 & 75 & 25 \\
7 & 50 & 50 \\
\hline
\end{tabular}

As composições da amostra referência ( $0 \%$ de lodo) com as porcentagens em massa de lodo 5\%, 10\%, 15\%, $20 \%$, $25 \%$ e $50 \%$, foram preparadas em moinho de bolas, em água, por aproximadamente $4 \mathrm{~h}$. Em seguida, as mesmas permaneceram na estufa por $24 \mathrm{~h}$ a $110^{\circ} \mathrm{C}$ e posteriormente a esse processo as amostras foram destorroadas em almofariz de porcelana e passadas na peneira com abertura $0,180 \mathrm{~mm}$ (\# 80 ABNT).

As composições foram conformadas por prensagem uniaxial na forma de barrinhas e sinterizadas num forno elétrico Jung, nas temperaturas de 900, 1000 e 1100 ${ }^{\circ} \mathrm{C}$, utilizando uma taxa de aquecimento de $10{ }^{\circ} \mathrm{C} / \mathrm{min} \mathrm{e}$ patamar de $2 \mathrm{~h}$. Para cada temperatura, foram sinterizadas 10 barrinhas de cada composição. Após a sinterização as amostras foram caracterizadas fisicamente a partir da determinação das medidas de absorção de água, porosidade aparente e módulo de ruptura à flexão em três pontos, feito numa máquina universal de ensaios Shimadzu, AG-I 10 $\mathrm{kN}$, com velocidade de aplicação de carga de $1,27 \mathrm{~mm} /$ min. A análise microestrutural das amostras foi feita por microscopia eletrônica de varredura, num equipamento Shimadzu SSX-550 com EDS acoplado. Para a análise das fases formadas após a sinterização, as amostras sinterizadas foram moídas em almofariz de ágata e foi feita a análise de difração de raios $\mathrm{X}$ em difratômetro Shimadzu XRD-6000, com radiação Cuk $\alpha$, varredura de $2^{\circ} / \mathrm{min}, 2 \theta$ de $5^{\circ}$ a $90^{\circ}$.

\section{RESULTADOS E DISCUSSÃO}

Na Tabela II está apresentada a composição química das matérias-primas. A mistura das argilas apresentou composição química semelhante à da maioria das argilas para o uso em cerâmica vermelha, ou seja, rica em sílica $(63,7 \%)$ e alumina $(25,5 \%)$ e de natureza não carbonática devido à ausência de $\mathrm{CaO}$. $\mathrm{O}$ teor de ferro $(6,09 \%)$ apresentou-se dentro dos valores considerados normais para a argila (entre 4 e $8 \%$ ), conferindo a coloração vermelha após a queima. A mistura de argilas, ainda apresentou 3,25\% de $\mathrm{K}_{2} \mathrm{O}$ e quantidades menores que $1 \%$ de óxidos de $\mathrm{K}, \mathrm{Mn}$, Ti e Zr. Em relação ao lodo da ETE, o mesmo foi constituído basicamente por $\mathrm{CaO}, \mathrm{Al}_{2} \mathrm{O}_{3}, \mathrm{SiO}_{2}, \mathrm{MgO}$ que correspondem a cerca de 83,27 \%. Destacou-se, nessa análise, a alta concentração de $\mathrm{CaO}$, proveniente da cal utilizada para o processo de estabilização do lodo. A calcinação do lodo a $1000{ }^{\circ} \mathrm{C}$ mostrou uma redução de $44,5 \%$ na massa, o que demonstra que o lodo possui grande quantidade de matéria orgânica.

Tabela II - Composição química (\% em massa) das matériasprimas.

[Table II - Chemical composition (wt.\%) of the raw materials.]

\begin{tabular}{ccc}
\hline Composição & $\begin{array}{c}\text { Mistura das Argilas } \\
(\%)\end{array}$ & $\begin{array}{c}\text { Lodo } \\
(\%)\end{array}$ \\
\hline $\mathrm{CaO}$ & - & 38,75 \\
$\mathrm{SiO}$ & 63,70 & 15,54 \\
$\mathrm{Al}_{2} \mathrm{O}_{3}$ & 25,51 & 15,01 \\
$\mathrm{MgO}$ & - & 12,66 \\
$\mathrm{Fe}_{2} \mathrm{O}_{3}$ & 6,09 & 10,98 \\
$\mathrm{SO}_{3}$ & - & 4,14 \\
$\mathrm{~K}_{2} \mathrm{O}$ & 3,25 & 0,96 \\
$\mathrm{TiO}_{2}$ & 0,98 & 1,73 \\
$\mathrm{MnO}_{\mathrm{ZnO}}$ & 0,41 & - \\
$\mathrm{ZnO}$ & 0,19 & - \\
\hline
\end{tabular}

As distribuições de tamanho de partículas da mistura das argilas e do lodo apresentadas na Fig. 1 mostraram que a argila apresentou um tamanho médio de partícula de $\mathrm{D}_{50}$ de $0,72 \mathrm{~mm}$ e uma faixa de tamanho de partícula estreita, com $\mathrm{D}_{10}$ de $0,57 \mathrm{~mm}$ e $\mathrm{D}_{90}$ de $1,33 \mathrm{~mm}$. Por outro lado, o lodo apresentou uma larga distribuição de tamanho de partículas, com $\mathrm{D}_{10}$ de $1,83 \mathrm{~mm}$ e $\mathrm{D}_{90}$ de $99,83 \mathrm{~mm}$ e tamanho médio de partícula $\mathrm{D}_{50}$ de $25,62 \mathrm{~mm}$. A distribuição de tamanho de partículas do lodo pode afetar principalmente a etapa de conformação dos corpos-de-prova, pois uma distribuição larga favorece um maior empacotamento das partículas. Porém, devido à alta perda ao fogo do lodo (em torno de $44,5 \%$ ), esse efeito não foi observado, após sinterização.

Nas Figs. 2 e 3 estão apresentados os difratogramas de raios $\mathrm{X}$ das misturas das argilas usada para a produção da 


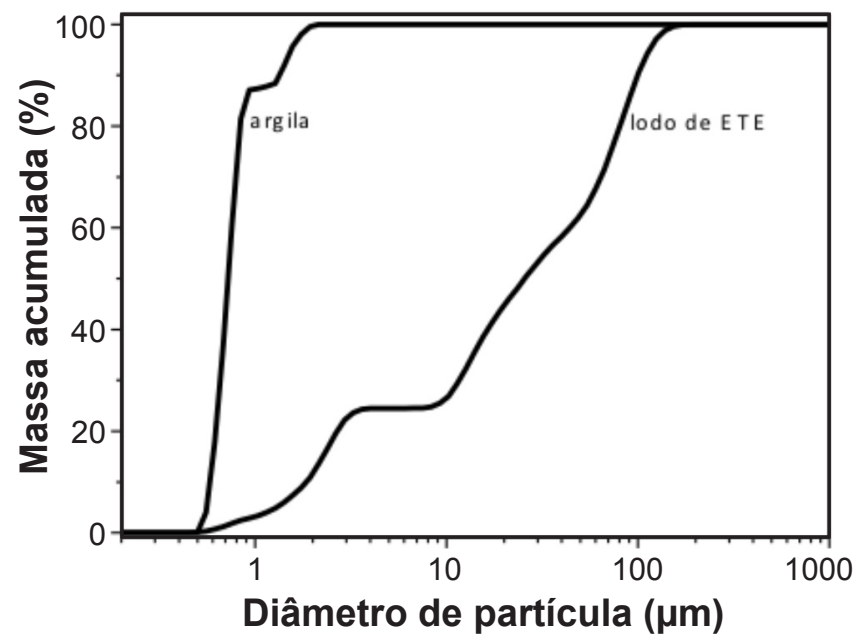

Figura 1: Distribuição de tamanho das partículas das matériasprimas.

[Figure 1: Particle size distribution of the raw materials.]

amostra de referência utilizada pela Cerâmica S. Gerônimo e do lodo da ETE Verde. Na Fig. 2, que representa o difratograma da mistura das argilas, destacaram-se os picos de difração das fases cristalinas do $\alpha$-quartzo $\left(\mathrm{SiO}_{2}\right)$, da caulinita e da ilita. A ausência de picos da fase cristalina $\mathrm{Fe}_{2} \mathrm{O}_{3}$ pode indicar que o ferro presente na composição química da argila, esteja em solução com outras fases ou esteja presente em fase amorfa, razão pela qual não foi detectada pela difração de raios X. Essas fases são características das argilas empregadas na fabricação de cerâmica vermelha, as quais apresentam cor vermelha quando sinterizadas a $950{ }^{\circ} \mathrm{C}$ [20]. Na difração de raios X do lodo, apresentada na Fig. 3, foram identificadas as fases de quartzo, carbonato de cálcio e caulinita. O carbonato de cálcio é oriundo do processo de higienização e estabilização do lodo e o quartzo e a caulinita provavelmente do tratamento de esgoto, pois nesse processo, o esgoto foi bombeado para caixas de areia para a separação

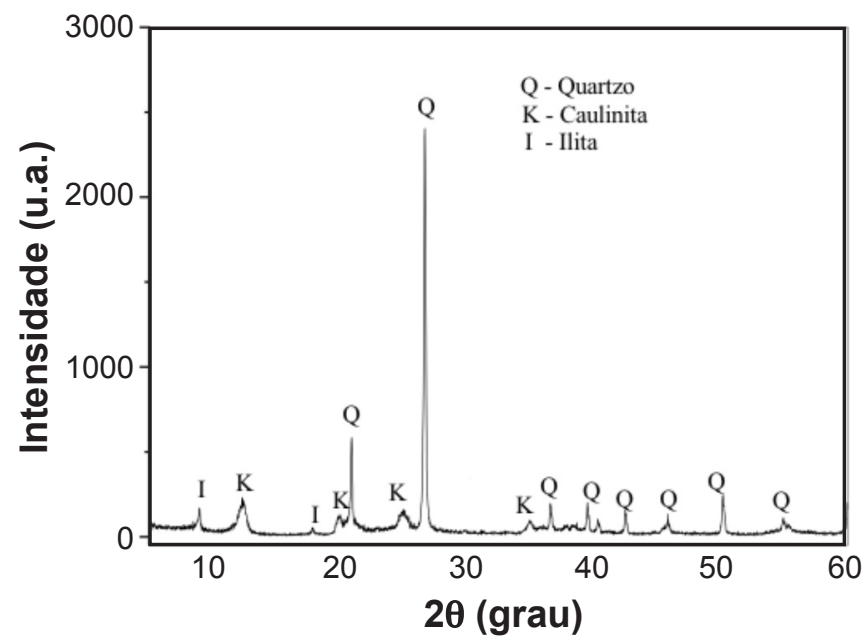

Figura 2: Difratograma de raios $\mathrm{X}$ da argila. Q - quartzo; K caulinita; I - Ilita.

[Figure 2: X-ray diffraction pattern of the clay. $Q$ - quartz; $C$ kaolinite; I - illite.]

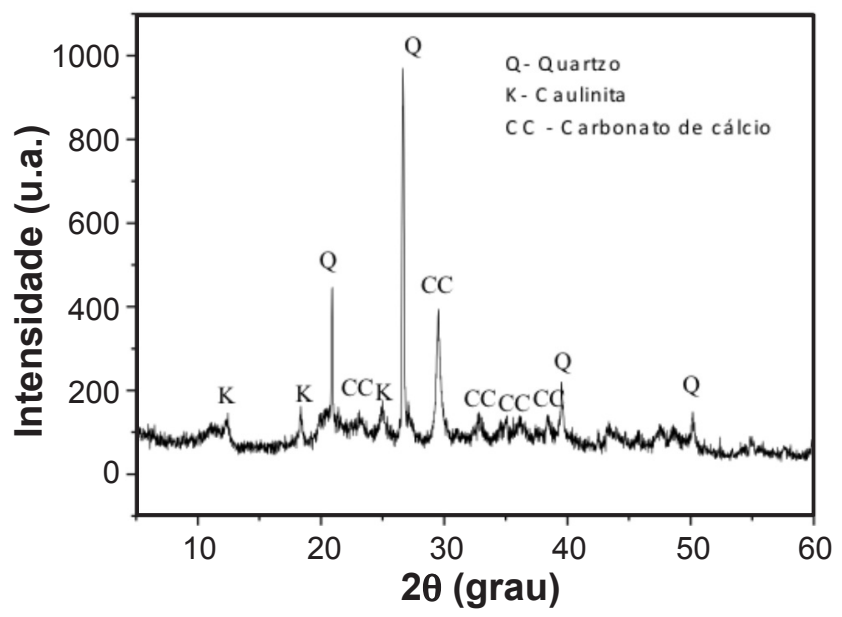

Figura 3: Difratograma de raios X do lodo de ETE. Q - quartzo; $\mathrm{K}$ - caulinita; CC - carbonato de cálcio.

[Figure 3: X-ray diffraction patterns of the sludge. $Q$ - quartz; $C$ kaolinite; CC - calcium carbonate.]

da matéria sólida grosseira.

A análise térmica diferencial e termogravimétrica (ATD/ TG) da mistura de argilas e do lodo está apresentada na Fig. 4 (a) e (b). Pelas curvas de ATD/TG da mistura de argilas foram observados dois picos endotérmicos, os quais estão acompanhados de perda de massa, sendo um na temperatura de $90{ }^{\circ} \mathrm{C}$, característico da perda de água livre e adsorvida e o outro a $525{ }^{\circ} \mathrm{C}$, característico da perda de hidroxilas, referente à desidroxilação da caulinita. Na análise do gráfico de TG foi observada uma perda de massa em torno de $2 \%$, correspondente à perda de água livre e outra perda de massa, entre 100 e $600{ }^{\circ} \mathrm{C}$ de aproximadamente $5 \%$, relativa à perda de hidroxilas e também de material orgânico presente nas argilas. Na temperatura de $940{ }^{\circ} \mathrm{C}$ foi observado um pico exotérmico, provavelmente relacionado à nucleação da mulita [20]. Na análise térmica ATD/TG do lodo foi observado também dois picos endotérmicos, acompanhados de perda de massa. O primeiro pico na temperatura de 100 ${ }^{\circ} \mathrm{C}$ é referente à perda de água adsorvida fisicamente. $\mathrm{O}$ segundo pico endotérmico a $810{ }^{\circ} \mathrm{C}$ pode ser atribuído à decomposição do carbonato de cálcio presente no lodo [21, 22], conforme a difração de raios $X$ apresentada na Fig. 3. Observou-se também uma perda de massa em quase toda faixa de temperatura que vai de $100^{\circ} \mathrm{C}$ até aproximadamente $810^{\circ} \mathrm{C}$, que é referente à perda de materiais orgânicos presentes no lodo.

Nas Figs. 5, 6e 7 estão apresentadas as difrações de raios $\mathrm{X}$ das composições de 1, 3 e 7 sinterizadas nas temperaturas de $900{ }^{\circ} \mathrm{C}, 1000^{\circ} \mathrm{Ce} 1100{ }^{\circ} \mathrm{C}$, respectivamente. Na Fig. 5 foi possível observar que a $900{ }^{\circ} \mathrm{C}$ e $1000{ }^{\circ} \mathrm{C}$ houve a presença predominantemente de quartzo e de mulita. A $1100{ }^{\circ} \mathrm{C}$ foi verificado também a presença da fase cristobalita, oriunda da transformação do quartzo. Para a composição 3, Fig. 5, foi observado que, a $1100{ }^{\circ} \mathrm{C}$, além dos picos referentes ao quartzo, mulita e cristobalita, também estavam presentes picos de anortita $\left(\mathrm{CaO} \cdot \mathrm{Al}_{2} \mathrm{O}_{3} \cdot 2 \mathrm{SiO}_{2}\right)$. Para a composição 7 , foi verificado que com o aumento da temperatura de sinterização, os picos da fase anortita se tornaram mais 

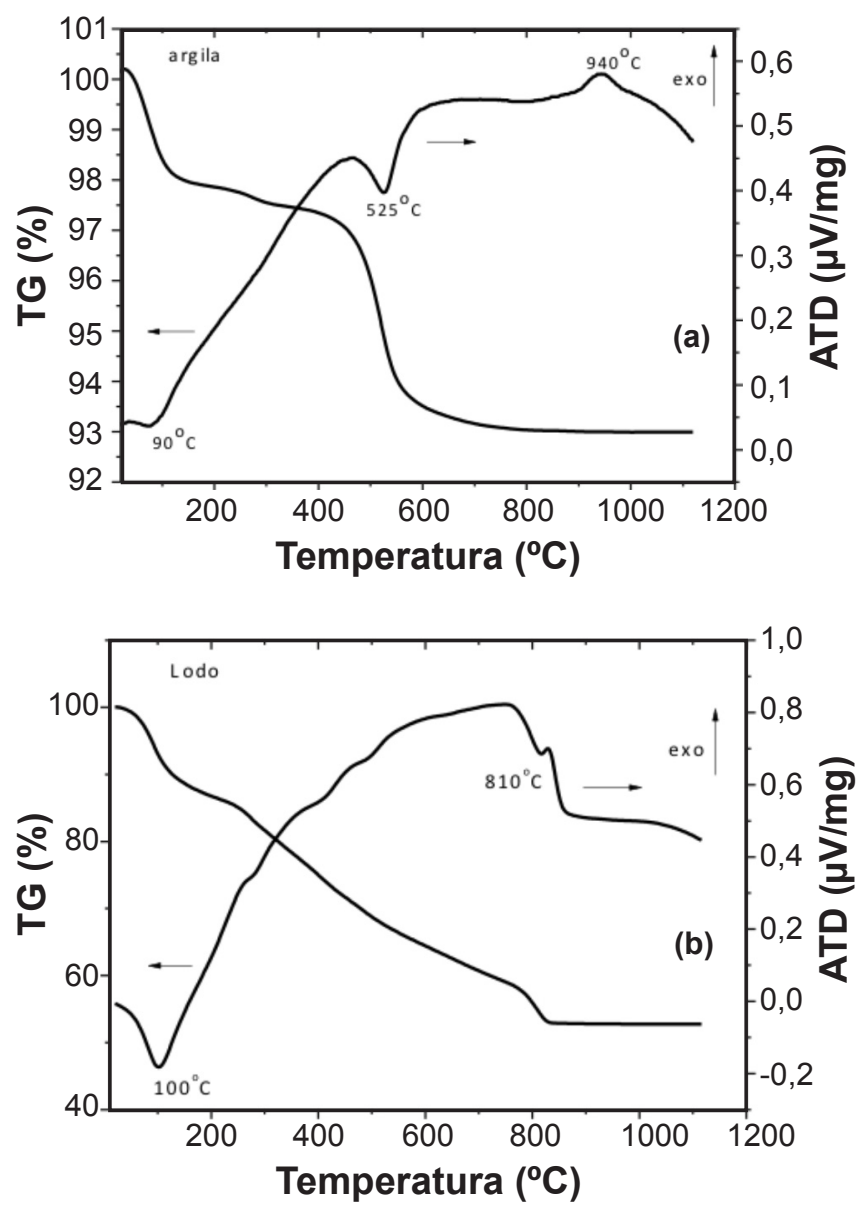

Figura 4: (a) e (b) Análise térmica diferencial e termogravimétrica: (a) mistura de argilas e (b) lodo.

[Figure 4: (a) and (b) Thermogravimetric and differential thermal analysis: (a) clay and (b) sludge.]

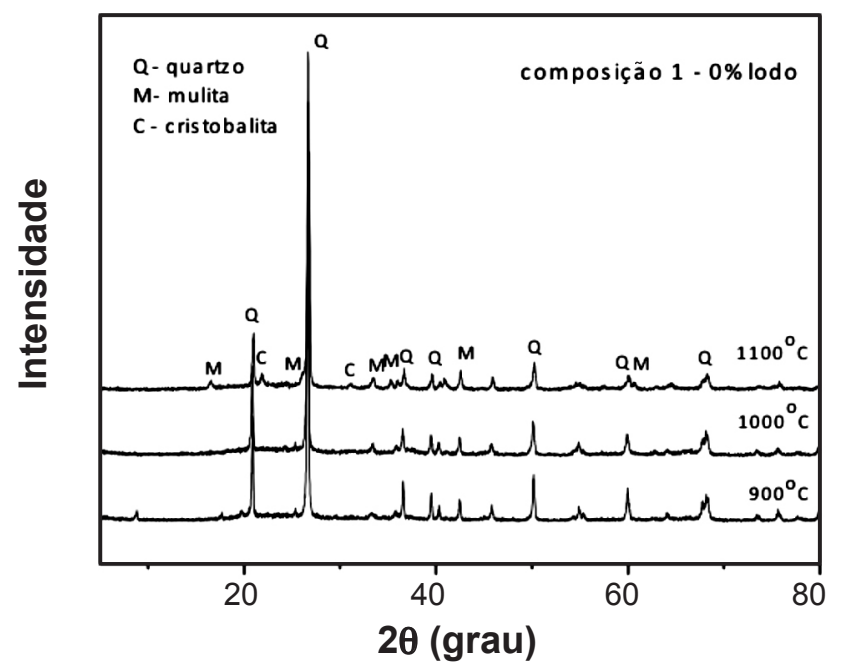

Figura 5: Difratogramas de raios $\mathrm{X}$ da composição 1 sinterizada a $900{ }^{\circ} \mathrm{C}, 1000{ }^{\circ} \mathrm{C}$ e $1100{ }^{\circ} \mathrm{C}$.

[Figure 5: X-ray diffraction patterns of the composition 1 sintered at $900{ }^{\circ} \mathrm{C}, 1000^{\circ} \mathrm{C}$ and $1100^{\circ} \mathrm{C}$.]

evidentes, indicando uma maior cristalização dessa fase. Foi possível observar também, picos referentes à fase volastonita $\left(\mathrm{CaSiO}_{3}\right)$.

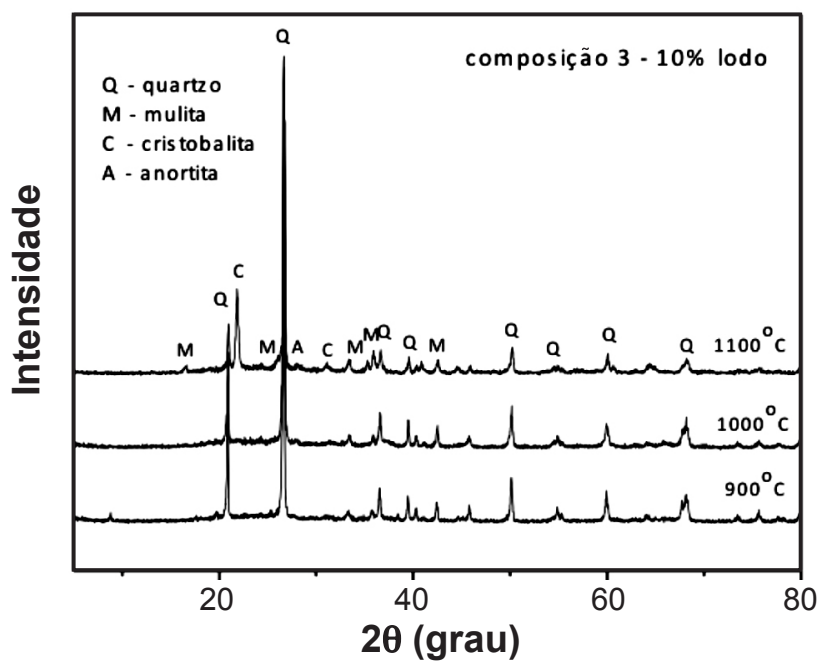

Figura 6: Difratogramas de raios $\mathrm{X}$ da composição 3 sinterizada a $900^{\circ} \mathrm{C}, 1000^{\circ} \mathrm{C}$ e $1100^{\circ} \mathrm{C}$.

[Figure 6: X-ray diffraction patterns of the composition 3 sintered at $900^{\circ} \mathrm{C}, 1000^{\circ} \mathrm{C}$ and $1100^{\circ} \mathrm{C}$.]

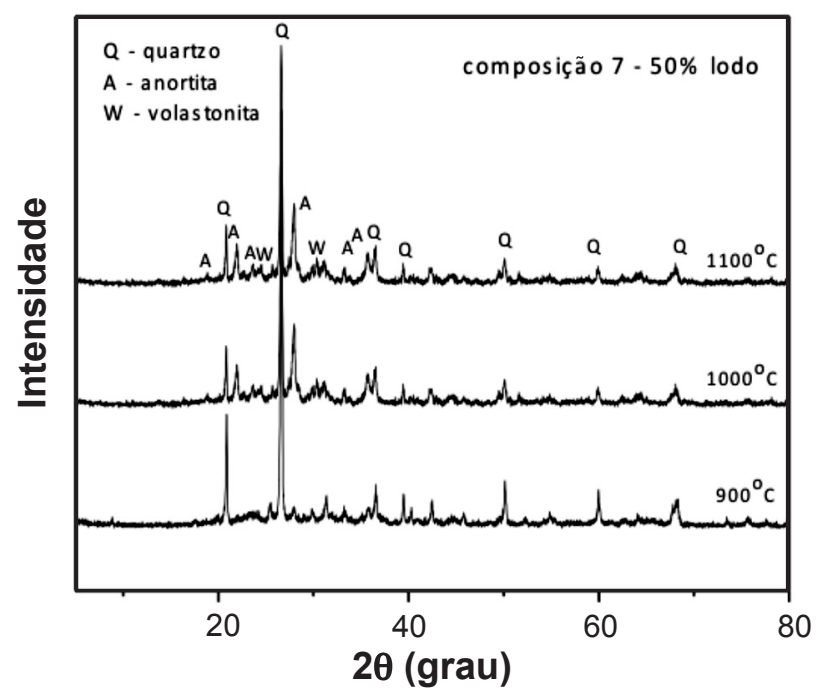

Figura 7: Difratogramas de raios $\mathrm{X}$ da composição 7 sinterizada a $900{ }^{\circ} \mathrm{C}, 1000{ }^{\circ} \mathrm{Ce} 1100^{\circ} \mathrm{C}$.

[Figure 7: X-ray diffraction patterns of the composition 7 sintered at $900^{\circ} \mathrm{C}, 1000^{\circ} \mathrm{C}$ and $1100^{\circ} \mathrm{C}$.]

Na Fig. 8, na qual está apresentado um difratograma com $2 \theta$ variando de 15 a $35^{\circ}$ de todas as composições estudadas, foi observado que com o aumento da adição de lodo na massa cerâmica, ocorreu o aparecimento das fases anortita e volastonita e a diminuição da fase mulita. A anortita é produto da reação entre o óxido de cálcio (proveniente da decomposição do carbonato de cálcio) com a metacaulinita (resultante da decomposição da caulinita) e o quartzo de granulometria fina. Este comportamento ocorre em materiais com concentração elevada de óxido de cálcio [23, 24]. Com a adição de até $10 \%$ de lodo (composição 2), a fase anortita ainda não pode ser observada, enquanto que para porcentagens maiores, a fase anortita aumentou com o aumento da quantidade de lodo. Para a composição com $25 \%$ de lodo (composição 6) foi possível observar um 


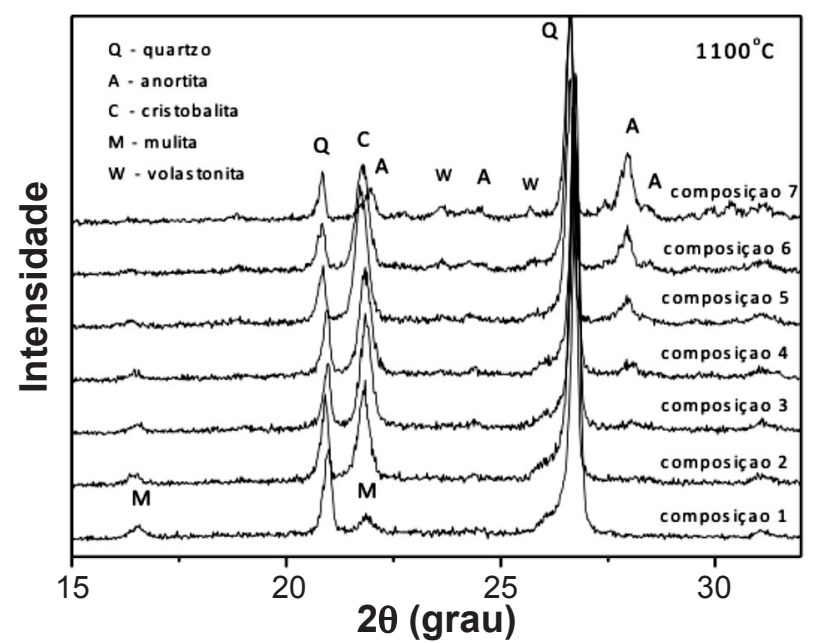

Figura 8: Difratogramas de raios $\mathrm{X}$ das composições sinterizadas a $1100{ }^{\circ} \mathrm{C}$

[Figure 8: X-ray diffraction patterns of the compositions of sintered at $\left.1100{ }^{\circ} \mathrm{C}.\right]$

aumento considerável da fase anortita enquanto que o teor de mulita diminuiu. Isso ocorreu porque provavelmente a $\mathrm{SiO}_{2}$ que seria utilizada para a formação da mulita foi sendo consumida para a formação de compostos com cálcio. Para a composição com $50 \%$ lodo, a mulita praticamente não apareceu [23, 24]. A presença da anortita e volastonita indica que o óxido de cálcio não permaneceu livre na massa cerâmica e, portanto passível de hidratação, mas reagiu, consumindo a fase metacaulinta e formando as fases cristalinas cálcicas [24]. O carbonato de cálcio, durante a queima é decomposto em óxido de cálcio $(\mathrm{CaO})$ e dióxido de carbono $\left(\mathrm{CO}_{2}\right)$. $\mathrm{O} \mathrm{CO}_{2}$ é liberado para atmosfera, enquanto que o $\mathrm{CaO}$, na presença de umidade pode sofrer hidratação, transformando-se em hidróxido de cálcio. Essa hidratação é responsável muitas vezes, pelo rompimento estrutural da peça cerâmica, pois com a formação do $\mathrm{Ca}(\mathrm{OH})$, ocorre um aumento do volume das moléculas, as quais causam tensões internas em vários pontos do corpo cerâmico [25].

$\mathrm{Na}$ Tabela III estão apresentados os resultados das análises químicas das composições 2, 4 e 7 . Na análise química dessas composições verificou-se a predominância de óxido de silício e óxido de alumínio, com uma quantidade crescente de óxido de cálcio proveniente do lodo adicionado.

Utilizando a análise química e com o auxílio do diagrama de fases óxido de alumínio - óxido de silício - óxido de cálcio, mostrado na Fig. 9 [26], verificou-se que o aumento da quantidade de óxido de cálcio fez com que as composições se deslocassem dentro do diagrama, indo do triângulo de compatibilidade da sílica-mulita-anortita para o triângulo de compatibilidade vizinho da sílica-anortita-volastonita, no qual a temperatura inicial de fusão é cerca de $200{ }^{\circ} \mathrm{C}$ mais baixa (teoricamente, de 1345 para $1170{ }^{\circ} \mathrm{C}$ ) e onde, a mulita é substituída pela volastonita $[27,28]$. No diagrama estão representadas as composições 1, 4 e 7. A composição 1 não apresentou cálcio na sua composição química, encontrandose localizada no lado do triangulo $\mathrm{SiO}_{2}-\mathrm{Al}_{2} \mathrm{O}_{3}$ e tendo como fases formadas a mulita e sílica, que encontra-se nesse caso,
Tabela III - Composição química (\% em massa) das amostras. [Table III - Chemical composition (wt.\%) of samples.]

\begin{tabular}{cccc}
\hline $\begin{array}{c}\text { Composição } \\
\text { química }\end{array}$ & $\begin{array}{c}\text { Composição } 2 \\
\text { (5\% de lodo) }\end{array}$ & $\begin{array}{c}\text { Composição } 4 \text { Composição } 7 \\
(15 \%\end{array}$ \\
\hline $\mathrm{CaO}$ & 1,12 & 3,41 & 14,15 \\
$\mathrm{SiO}$ & 64,77 & 60,22 & 46,39 \\
$\mathrm{Al}_{2} \mathrm{O}_{3}$ & 23,08 & 22,76 & 21,31 \\
$\mathrm{MgO}$ & ---- & 1,96 & 6,44 \\
$\mathrm{Fe}_{2} \mathrm{O}_{3}$ & 6,53 & 6,93 & 7,87 \\
$\mathrm{SO}_{3}$ & 3,18 & 0,19 & ---- \\
$\mathrm{K}_{2} \mathrm{O}$ & 3,25 & 3,14 & 2,19 \\
$\mathrm{TiO}_{2}$ & 1,01 & 1,08 & 1,23 \\
$\mathrm{MnO}_{\mathrm{ZnO}}$ & 0,27 & 0,26 & 0,24 \\
$\mathrm{ZrO}$ & 0,04 & 0,04 & 0,05 \\
$\mathrm{~V}_{2} \mathrm{O}_{5}$ & ---- & ---- & ---- \\
$\mathrm{ZnO}$ & ---- & ---- & 0,08 \\
$\mathrm{CuO}$ & ---- & ---- & 0,04 \\
\hline
\end{tabular}

na forma de quartzo e cristobalita. A composição 4 encontrase dentro do triângulo de compatibilidade da mulita-sílicaanortita, sendo essas as principais fases detectadas na difração de raios X. A composição 7 está localizada no triângulo de compatibilidade da anortita-sílica-volastonita, sendo que pela difração de raios $X$, observou-se a presença das fases da sílica (na forma polimórfica do quartzo), anortita e picos menos intensos de volastonita.

Nas Figs. 10 e 11 estão apresentadas a variação da absorção de água (AA) e da porosidade aparente (PA) com a temperatura de sinterização para as composições estudadas, respectivamente. Observou-se que com o aumento da

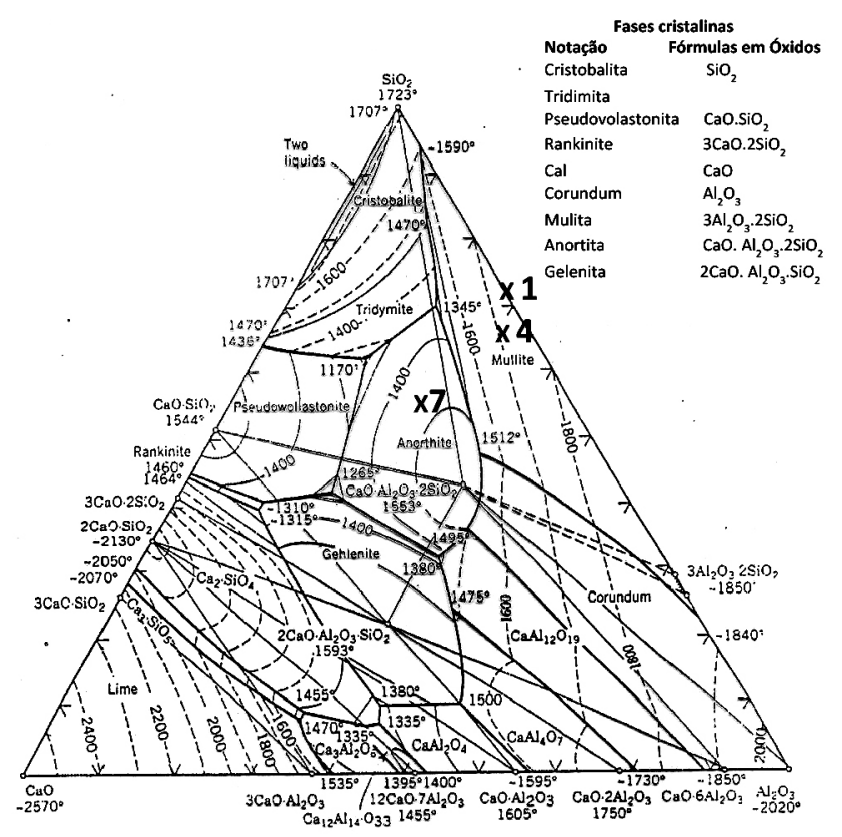

Figura 9: Diagrama de fases do sistema $\mathrm{SiO}_{2}-\mathrm{Al}_{2} \mathrm{O}_{3}-\mathrm{CaO}$. [Figure 9: Phase diagram of the system $\mathrm{SiO}_{2}-\mathrm{CaO}-\mathrm{Al}_{2} \mathrm{O}_{3}$.] 


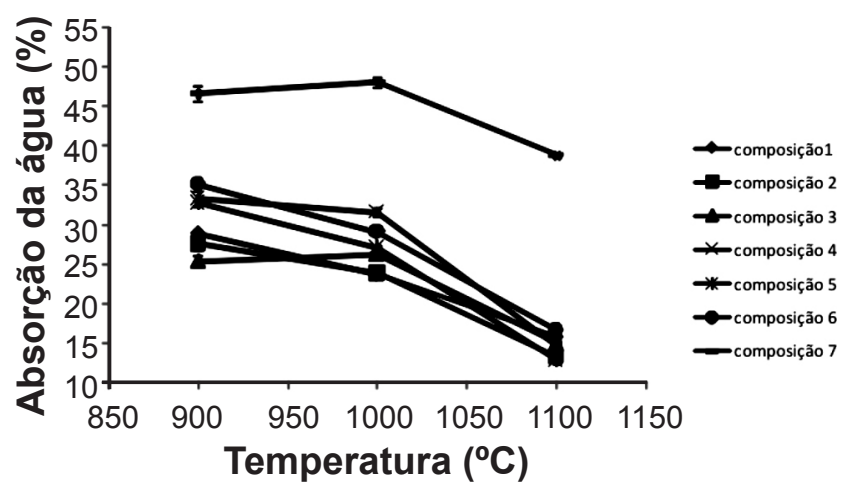

Figura 10: Absorção de água dos corpos de prova após sinterização. [Figure 10: Water absorption of specimens after sintering.]

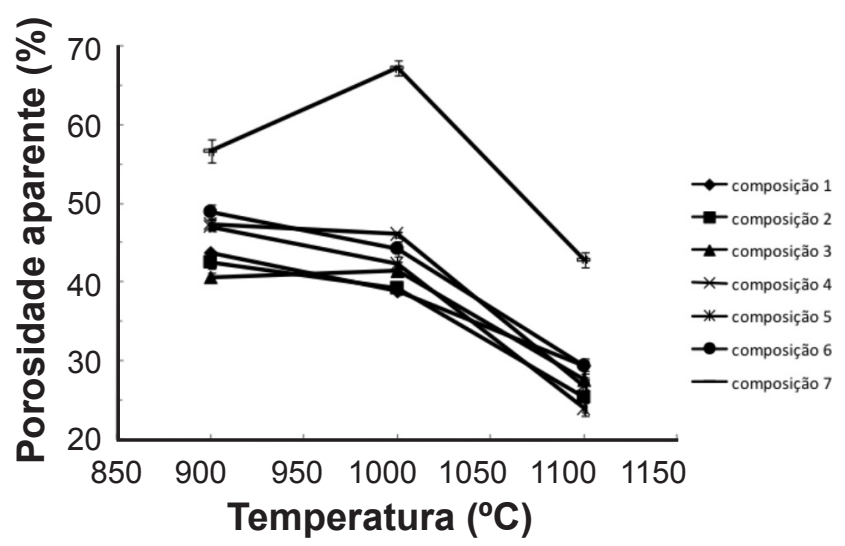

Figura 11: Porosidade aparente dos corpos de prova após sinterização.

[Figure 11: Apparent porosity of the specimens after sintering.]

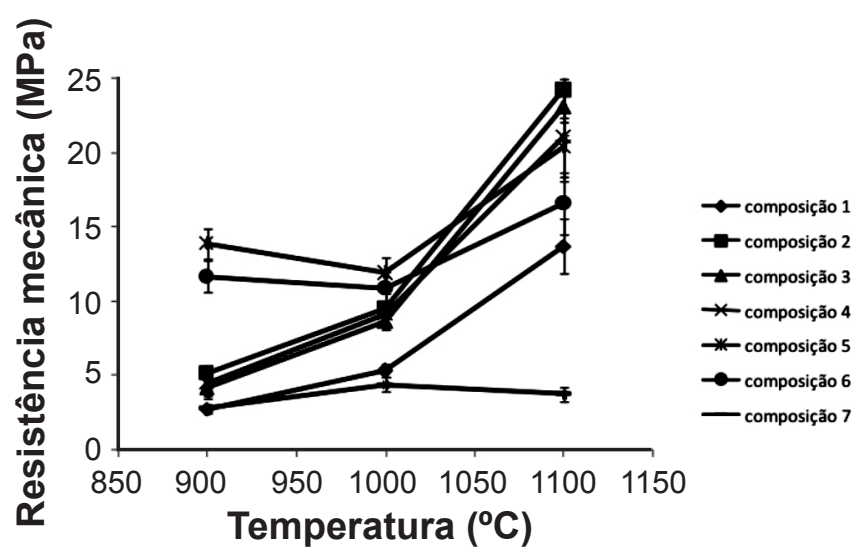

Figura 12: Módulo de ruptura a flexão dos corpos de prova após sinterização.

[Figure 12: Tensile modulus of rupture of the specimens after sintering.]

temperatura houve uma diminuição da absorção de água e da porosidade aparente para as todas as composições, excetuando-se a composição 7. Essas propriedades estão associadas ao tipo de microestrutura formada no corpo sinterizado, e estão relacionadas com a densificação da massa cerâmica e com o aumento da temperatura de sinterização. Com relação à quantidade de lodo adicionada, observou-se que os valores de AA e PA tiveram uma maior variação entre as composições para as temperaturas de 900 e $1000{ }^{\circ} \mathrm{C}$ com a adição de até $25 \%$ de lodo (composição 6). Para essas composições, na temperatura de sinterização de $1100{ }^{\circ} \mathrm{C}$, a absorção de água ficou em torno de $16,6 \%$, indicando que é possível a incorporação de lodo em até $25 \%$ em massa sem grande variação nessa propriedade. Já a amostra 7 , com $50 \%$ de adição de lodo, apresentou uma absorção de água nas temperaturas de sinterização estudadas entre 38,8\% a 46,6\%, bem superiores às outras composições. Esse aumento na AA e PA podem ser atribuídos a grande quantidade de matéria orgânica presente no lodo, que ao ser ignizada, deixou uma maior quantidade de porosidade entre os grãos os quais são mais difíceis de serem preenchidos pela fase líquida da massa.

Os resultados do módulo de ruptura à flexão dos corpos de prova em função da temperatura de sinterização para todas as composições estudadas estão apresentados na Fig. 12. Pode-se observar que a resistência à flexão aumentou com $o$ aumento da temperatura de sinterização, pois com o aumento da temperatura ocorreu uma diminuição da porosidade aberta no material, e um maior grau de densificação. Outro fator observado foi que ocorreu um aumento do módulo de ruptura com a adição de até $20 \%$ de lodo em relação à composição sem a adição de lodo. O módulo de ruptura da amostra referência (sem adição de lodo) foi de 13,7 $\pm 1,8$ $\mathrm{MPa}$ na temperatura de sinterização de $1100{ }^{\circ} \mathrm{C}$ enquanto para as composições com a adição de lodo, a resistência aumentou para 24,2 $\pm 2,1 \mathrm{MPa}$ com 5\% de lodo, 23,0 \pm 1,9 MPa com $10 \%$ de lodo, 21,1 $\pm 2,5 \mathrm{MPa}$ com $15 \%$ de lodo e de 20,3 $\pm 2,0 \mathrm{MPa}$ com $20 \%$ de lodo. A resistência mecânica alcançada pela composição $6(16,6 \pm 2,0 \mathrm{MPa})$ foi praticamente a mesma da composição 1 e somente a composição 7 (adição de 50\% de lodo) apresentou uma diminuição da resistência mecânica $(3,78 \pm 0,5 \mathrm{MPa})$. Para as composições que tiveram a adição de lodo (composições de 2 a 7), verificou-se que o aumento da quantidade de lodo na massa provocou uma diminuição na resistência mecânica. A resistência à flexão das amostras sinterizadas depende do balanço entre a porosidade aparente e a quantidade de fases cristalinas de elevada resistência mecânica [23].

Uma das fases presentes nas composições com lodo foi a anortita, que é uma fase que apresenta uma alta resistência mecânica. A fase anortita foi detectada na difração de raios $\mathrm{X}$ dessas composições. Assim, a presença de anortita, juntamente com a fase cristalina da mulita pode ter ocasionado esse aumento de resistência mecânica. Quanto ao efeito da porosidade, pode ser observado pela Fig. 11 que a PA das composições aumenta com o aumento da quantidade de lodo adicionada, devido a presença de grande quantidade de material orgânico presente no lodo. Assim, a diminuição da resistência mecânica com a adição de maiores quantidades de lodo pode ser atribuída a esse aumento de PA. Já para a composição 7, a resistência mecânica diminuiu, pois a porosidade aparente foi bem mais alta e praticamente não houve mais a presença da fase mulita.

Na Fig. 13 são apresentadas as micrografias de todas as 
(a)

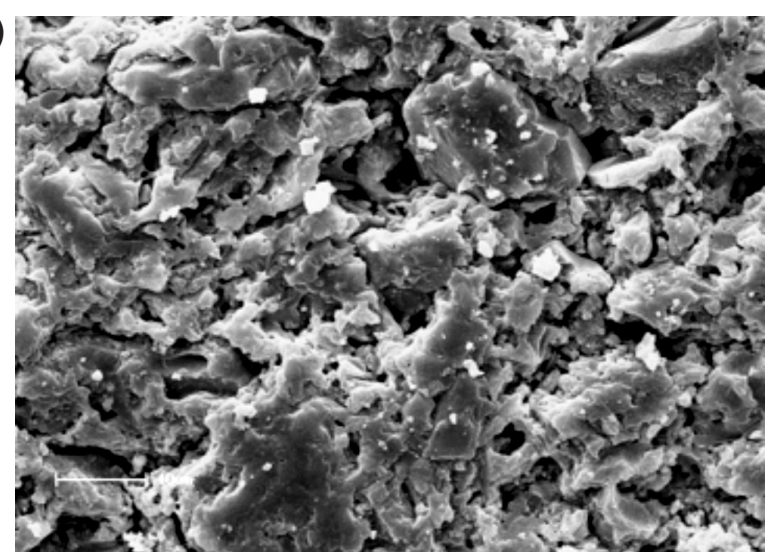

(c)

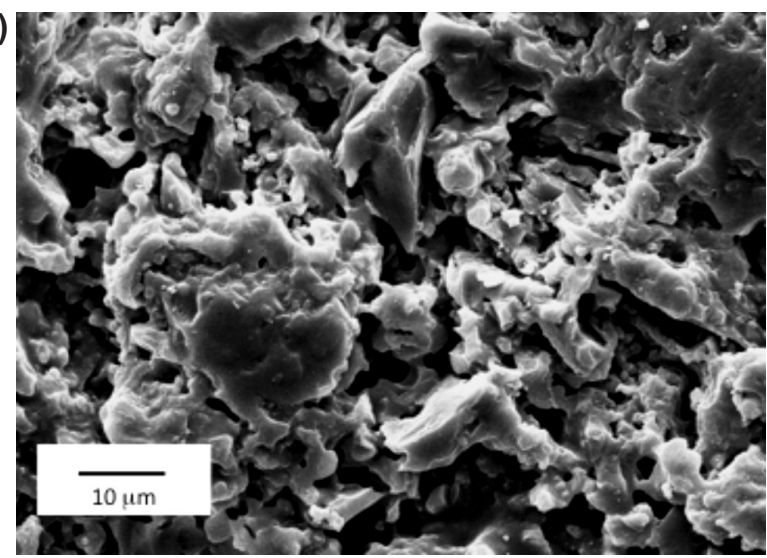

(e)

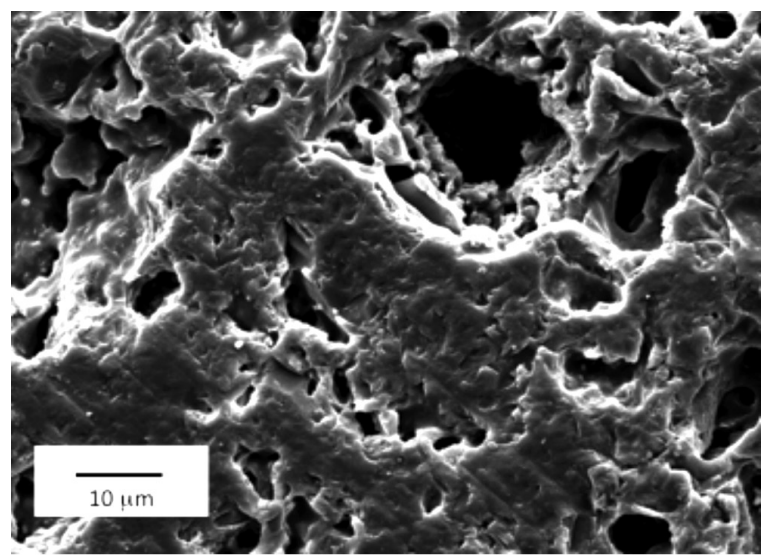

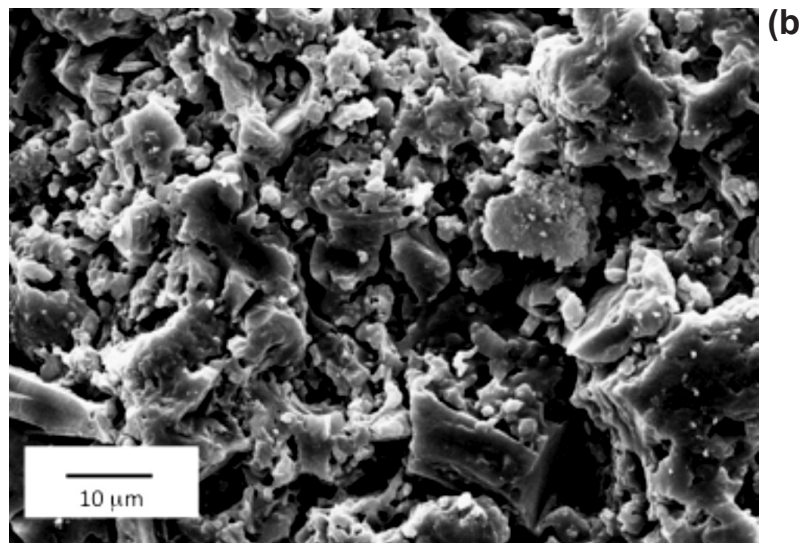

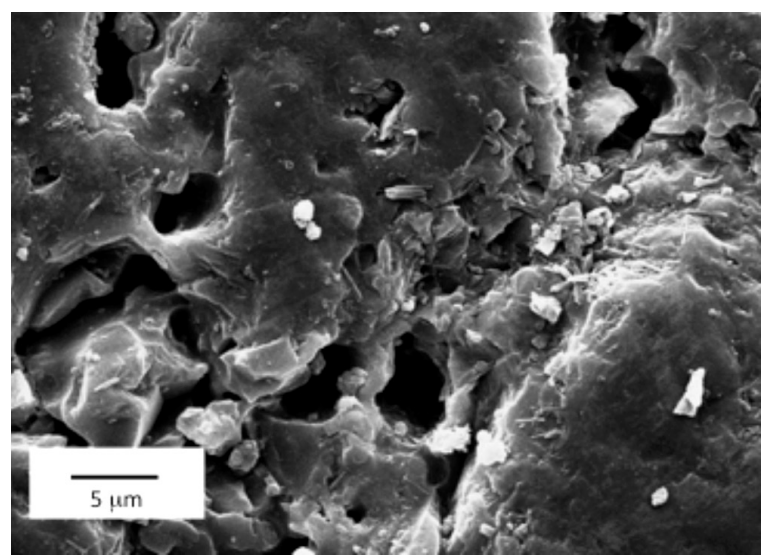

(d)
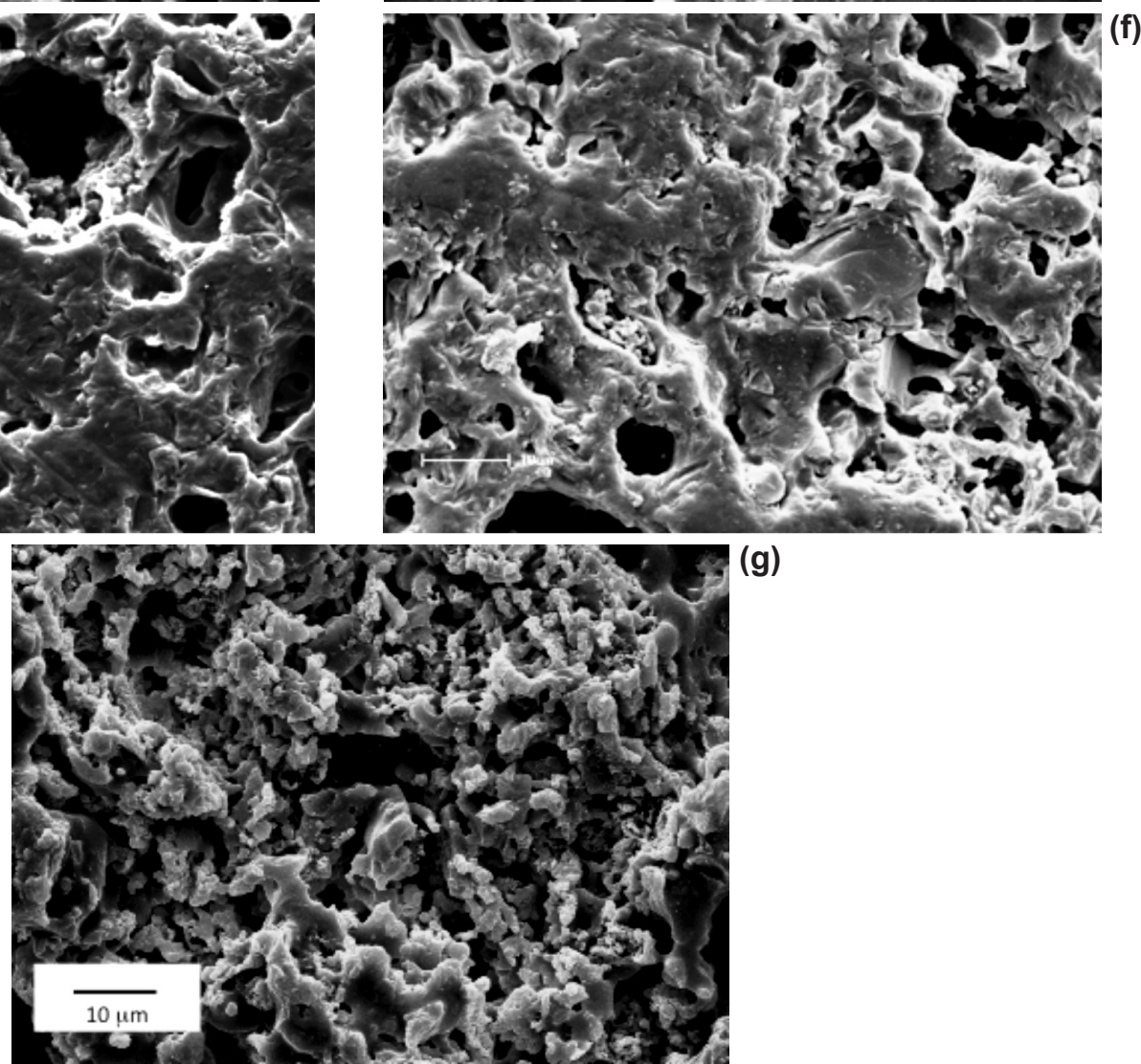

Figura 13 (a) e (b): Micrografias obtidas em microscópio eletrônico de varredura de todas as composições estudadas sinterizadas a $1100{ }^{\circ} \mathrm{C}$ : (a) composição 1; (b) composição 2; (c) composição 3; (d) composição 4; (e) composição 5; (f) composição 6 e (g) composição 7. [Figure 13: (a) and (b) SEM micrographs of all compositions studied sintered at $1100{ }^{\circ} \mathrm{C}:$ (a) composition 1; (b) composition 2; (c) composition 3; (d) composition 4; (e) composition 5; (f) composition 6 and $(g)$ composition 7.$]$ 

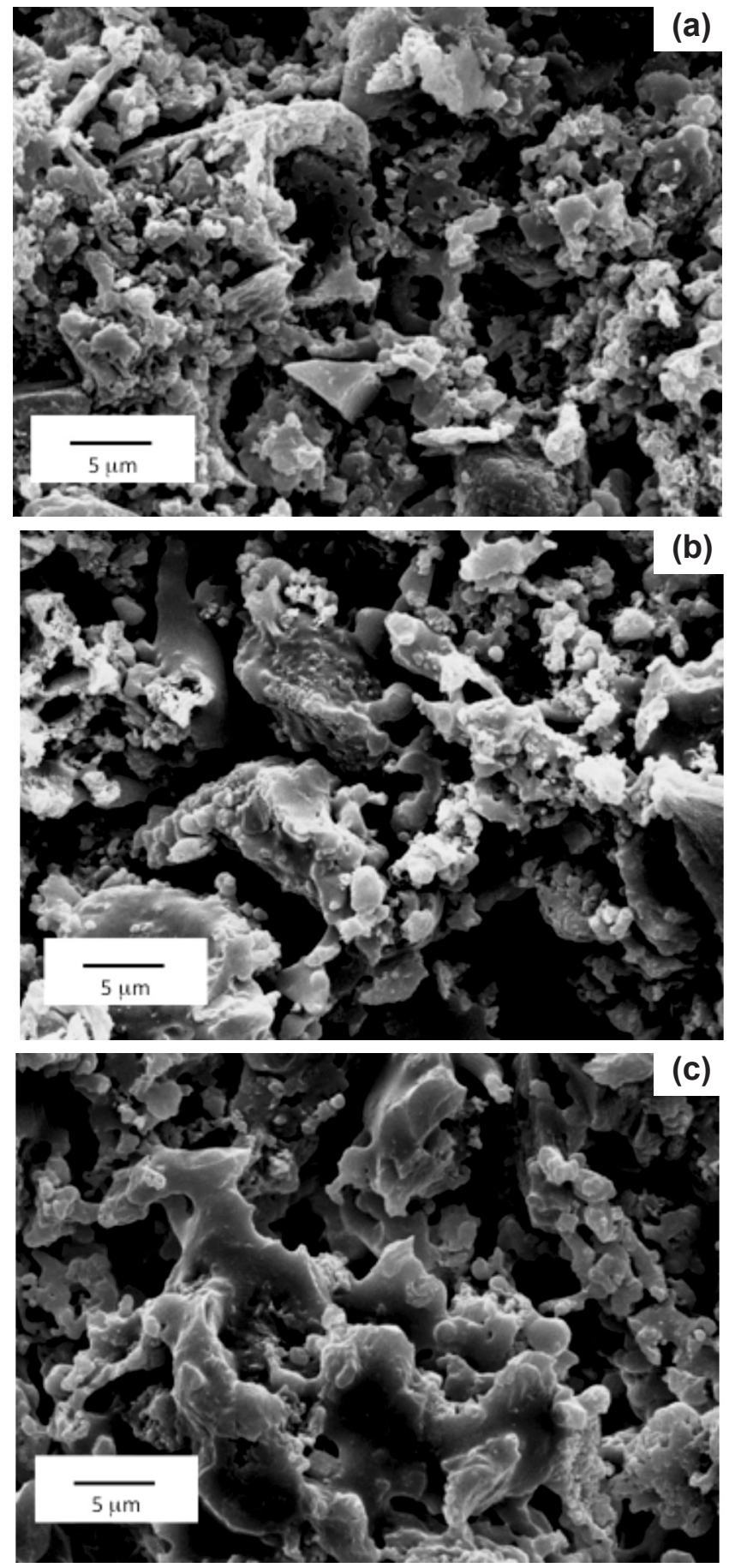

Figura 14: Micrografias obtidas em microscópio eletrônico de varredura das amostras da composição 7 (50\% lodo) sinterizadas nas temperaturas: (a) $900{ }^{\circ} \mathrm{C}$; (b) $1000{ }^{\circ} \mathrm{C} \mathrm{e} \mathrm{(c)} 1100{ }^{\circ} \mathrm{C}$.

[Figure 14: SEM micrographs of composition 7 (50\% sludge) sintered at temperatures (a) $900{ }^{\circ} \mathrm{C}$; (b) $1000^{\circ} \mathrm{C}$ and (c) $\left.1100^{\circ} \mathrm{C}.\right]$

composições estudadas sinterizadas a $1100{ }^{\circ} \mathrm{C}$. Observou-se que todas as composições apresentaram uma microestrutura porosa o que corrobora os resultados encontrados para PA e AA. Para as amostras com quantidades de lodo de 5 a $25 \%$ (composição de 2 a 6 ) o aumento da quantidade de lodo levou a um aumento na quantidade de fase líquida formada durante a sinterização. Isto pode ser verificado por um aumento na formação de poros arredondados com o aumento da quantidade de lodo. Os poros arredondados são poros característicos da presença de fase líquida. Este efeito é mais pronunciado para as composições com 15, 20 e $25 \%$ de lodo. Outra evidência do aumento da fase líquida é uma maior união de partículas gerando regiões menos porosas. A maior formação da fase líquida pode ser atribuída à maior quantidade de cálcio presente na composição, o que provoca a formação de fases cálcicas e o deslocamento da composição para um triângulo de compatibilidade onde a formação da fase líquida se dá em menor temperatura, como já discutido anteriormente. Já quando a quantidade de lodo é muito alta, como no caso da composição 7 , que possui $50 \%$ lodo na sua formulação, a porosidade verificada é bem maior, apesar da fase líquida formada. Isso pode ser atribuído a alta quantidade de matéria orgânica presente no lodo.

As micrografias da composição 7 (50\% de lodo) para as temperaturas de sinterização de 900,1000 e $1100{ }^{\circ} \mathrm{C}$ são mostradas nas Figs. 14 a, b e c. Observa-se que essa composição apresentou uma alta porosidade mesmo para a temperatura de $1100{ }^{\circ} \mathrm{C}$. Esse fato pode ser comprovado pelos altos valores de porosidade aparente e absorção de água já apresentados. A $1100{ }^{\circ} \mathrm{C}$ (Fig. 14c) pode-se observar que houve a formação de uma pequena quantidade de fase líquida. Isto pode ser evidenciado pela tendência de arredondamento dos poros e pelo aumento das regiões com partículas unidas e menos porosas. Nestas regiões pode ser observado que as superfícies das partículas são mais arredondadas, típico de regiões com presença de fase líquida durante a sinterização. Embora ocorra um pequeno aumento da quantidade de fase líquida, ela ainda é insuficiente para promover a densificação do material. Observa-se também nessas imagens que a microestrutura é mais porosa quando comparada com as outras composições.

\section{CONCLUSÕES}

Os resultados apresentados mostraram que é viável a utilização do lodo de ETE até a adição de $25 \%$ em massa para a temperatura de sinterização de $1100^{\circ} \mathrm{C}$, pois até essa quantidade de lodo, o valor de resistência mecânica alcançado foi praticamente igual ao da massa cerâmica sem adição de lodo e a absorção de água ficou dentro dos parâmetros exigidos pelas normas técnicas. A adição de lodo na dosagem de 50\% na massa cerâmica acarretou uma alta absorção de água nas temperaturas de sinterização estudadas, em torno de $38 \%$ na temperatura de sinterização de $1100{ }^{\circ} \mathrm{C}$, devido a grande quantidade de porosidade gerada pela presença de matéria orgânica proveniente do lodo. Com o aumento de porcentagem de lodo na massa cerâmica, foi observada a formação da fase anortita, o que indica que o óxido de cálcio proveniente do lodo foi totalmente consumido para a formação de fases cristalinas cálcicas, evitando assim o problema de hidratação do $\mathrm{CaO}$. A resistência mecânica da massa cerâmica com a adição do lodo pode ser atribuída tanto à presença dessas fases sólidas cálcicas quanto à sua porosidade aparente. A maior formação de fase líquida 
com o aumento da quantidade de lodo adicionado ocorreu devido à maior quantidade de óxido de cálcio presente na composição.

\section{REFERÊNCIAS}

[1] ABNT - Associação Brasileira de Normas Técnicas, "Resíduos Sólidos - Classificação", NBR 10004, Rio de Janeiro, RJ (2004).

[2] Lei No 12.305 - "Política Nacional de Resíduos Sólidos", Brasília, DF (2010).

[3] J. G. Machado Filho, Comunicação pessoal, SANEPAR - Unidade Regional de Ponta Grossa (URPG), Operação de esgoto, Ponta Grossa, PR (2012).

[4] T. S. Malta. Diss. Mestrado, Fund. Oswaldo Cruz, Escola Nacional de Saúde Pública, Rio de Janeiro, RJ (2001).

[5] F. S. Campos, M. C. Alves, R. Bras. Ci. Solo 32 (2008)1389.

[6] W. Bettiol, R. Ghini, App. Env. Soil Sci. 2011 (2011) 1. [7] Brasil, lei 12.651/2012, institui o novo Código Florestal, Brasília, DF, Presidência da República (2012).

[8] R. R. Menezes, G. A. Neves, H. C. Ferreira, R. Bras. Eng. Agríc. Ambiental 6 (2002) 303.

[9] M. Barakat, Diss. Mestrado, Univ. Federal do Paraná, Curitiba, PR (2009).

[10] L. C. S. Herek, A. T. Silva Junior, C. C. Pavezzi, R. Bergamasco, C. R. G. Tavares, Cerâmica 55, 326 (2009) 326.

[11] S. P. Taguchi, J. C. Santos, T. M. Gomes, N. A. Cunha, Cerâmica 60, 354 (2014) 291.

[12] M. Weizenmann, F. R. Bruxel, E. R. R. Santana, E. C. Oliveira, Cerâmica 59, 351 (2013) 442.
[13] D. V. Rodrigues, G. C. Xavier, F. Saboya, P. C. A Maia, J. Alexandre, Cerâmica 58, 347 (2012) 286.

[14] L. P. Rodrigues, J. N. F. Holanda, Cerâmica 59, 352 (2013) 551.

[15] R. Tartari, A. N. Módenes, S. A. Pianaro, N. Díaz-Mora, Cerâmica 57, 344 (2011) 387.

[16] S. R. Teixeira, S. A. de Souza, N. R. de Souza, P. Aléssio, G. T. A. Santos, Cerâmica 52, 323 (2006) 215.

[17] J. P. D. Vitorino, S. N. Monteiro, C. M. F. Vieira, Cerâmica 55, 336 (2009) 385.

[18] C. C. Díaz, Diss. Mestrado, Univ. de S. Paulo, S. Paulo, SP (2013) 197p.

[19] P. L. T. Velho, A. M. Bernardin, Ceram. Ind. 16 (2011) 20.

[20] P. S. Santos, "Ciência e Tecnologia de Argilas", $3^{a}$ Ed., Vol. 1, Edgard Blücher Ltda., S. Paulo, SP (1997).

[21] K. Traoré, T. S. Kabré, P. Blanchart, Ceram. Int. 29, 4 (2003) 377.

[22] S. J. G. Sousa, J. N. F. Holanda, Cerâmica 51, 317 (2005) 70 .

[23] L. F. B. Marino, A. Boschi, Ceram. Ind. 3 (1998) 18.

[24] C. Lira, O. E. Alarcon, M. D. M. Silveira, J. A. A. Bianchi, E. L. Honorato, L. Costa, Ceram. Ind. 2 (1997) 27. [25] J. C. S. Oliveira, B. B. Lira, Y. P. Yadava, C. M. M. Silva, T. W. G. Santos, Ceram. Ind. 16 (2011) 34.

[26] E. M. Levin, C. R. Robbins, H. F. McMurdie, "Phase Diagrams for Ceramists", The Am. Ceram. Soc., Columbus, Ohio, EUA (1974) Fig. 132, 2493.

[27] J. B. Silva, D. Hotza, A. M. Segadães, W. Acchar, Cerâmica 51, 320 (2005) 325.

[28] A. M. Segadães, M. A. Carvalho, W. Acchar, Appl. Clay Sci. 30 (2005) 42.

(Rec. 30/07/2014, Rev. 11/12/2014, Ac. 12/12/2014) 